Revista Brasileira de Agricultura Irrigada v.11, nº.5, p. 1756 - 1762, 2017

ISSN 1982-7679 (On-line)

Fortaleza, CE, INOVAGRI - http://www.inovagri.org.br

DOI: $10.7127 /$ rbai.v11n500801

Protocolo 801.17 - 23/05/2017 Aprovado em 31/08/2017

\title{
FORNECIMENTO RELATIVO DE IRRIGAÇÃO COMO ESTRATÉGIA DE GESTÃO DO DISTRITO DE IRRIGAÇÃO
}

José Aguiar Beltrão Júnior ${ }^{1}$, Raimundo Nonato Távora Costa ${ }^{2}$, Silvio Carlos Ribeiro Vieira Lima $^{3}$, Luciano Mateos Iñguez ${ }^{4}$, Paulo Gleisson Rodrigues de Sousa ${ }^{5}$

\section{RESUMO}

A pesquisa teve como objetivo utilizar o indicador Fornecimento Relativo de Irrigação (FRI), do software S@I, como estratégia para análise de indicadores de desempenho do Distrito de Irrigação com vista à sustentabilidade hídrica e econômica do Perímetro Irrigado Baixo Acaraú. Foi desenvolvido no Baixo Acaraú um modelo de Serviço de Assessoramento ao Irrigante (SAI) constituído por um software (S@I) para serviços via web (Web Service) com envio de informações diárias aos irrigantes do tempo de irrigação definidos com base na metodologia do balanço hídrico climatológico. Para o cálculo do FRI foi considerado o período de agosto a novembro nos anos de 2012 a 2014, em lotes de pequenos produtores. Para a avaliação de desempenho do Distrito de Irrigação foram utilizados os indicadores Eficiência Financeira, Produtividade da Água, Custo de Um Hectare em Produção e taxa de inadimplência da tarifa de água $\mathrm{K}_{2}$. Os resultados permitiram concluir que o FRI auxiliou na gestão do Dibau identificando os agricultores que utilizam água sem princípios técnicos, e foi importante na administração auxiliando na tomada de decisão e permitindo um equilíbrio na gestão do Dibau em meio à crise hídrica.

Palavras-chave: Gestão; Autossustentabilidade; Distrito de Irrigação.

\section{RELATIVE PROVISION OF IRRIGATION AS AN IRRIGATION DISTRICT MANAGEMENT STRATEGY}

\section{SUMMARY}

The objective of this research was to use the Irrigation Relative Supply (FRI) indicator of the S@I software as a strategy for the analysis of performance indicators of the Irrigation District with a view to the water and economic sustainability of the Acaraú Low Irrigated Perimeter. An Irrigante Advisory Service (SAI) model was developed in Baixo Acaraú, consisting of software (S @ I) for web services (Web Service) with daily information sent to the irrigation

\footnotetext{
${ }^{1}$ Ms. em Irrigação e Drenagem, UFC, joseaguiarjunior@yahoo.com.br;

${ }^{2}$ Prof. Dr. em Irrigação e Drenagem, UFC, rntcosta@secrel.com.br;

${ }^{3}$ Dr. em Irrigação e Drenagem, USP, silviocarlos@yahoo.com.br;

${ }^{4}$ Prof. Dr. Instituto de Agricultura Sostenible, luciano.mateos@ias.csic.es;

${ }^{5}$ Ms. em Eng. Agrícola, UFC, paulo.ufc.agro@gmail.com.
} 
time irrigators defined based on the methodology of the Climatic water balance. For the calculation of the FRI was considered the period from August to November in the years 2012 to 2014, in lots of small producers. For the performance evaluation of the Irrigation District, the indicators Financial Efficiency, Water Productivity, Cost of One Hectare in Production and rate of default of $\mathrm{K}_{2}$ water tariff were used. The results allowed us to conclude that the FRI assisted in the management of the Dibau identifying the farmers who use water without technical principles and was important in the administration, helping in the decision making and allowing a balance in the management of the Dibau in the midst of the water crisis.

Keywords: Management; Self-sustainability; Irrigation District.

\section{INTRODUÇÃO}

A região Nordeste do Brasil apresenta como fator de destaque suas características edafoclimáticas, particularmente relacionadas às irregularidades do clima, principais responsáveis pelo problema das secas a tempos enfrentados pela sociedade nordestina (GALVÍNCIO \& MOURA, 2005).

Em meio à distribuição irregular e quantidade insuficiente de precipitação pluviométrica, a população tem na agricultura irrigada uma opção estratégica importante no processo de desenvolvimento setorial e regional (FRANÇA, 2001).

Para incentivar a agricultura irrigada no Brasil, o Governo construiu os perímetros irrigados. Em 2013, foi promulgada a Lei $n^{\circ}$ 12.787 que dispõe sobre a Política Nacional de Irrigação tendo a transferência de gestão como sendo um dos seus aspectos que merecem destaque (PEREIRA et al., 2015).

No entanto, a prática da irrigação, exclusivamente, não é suficiente para promover um sistema sustentável aos agricultores, já que em muitos casos estes projetos dependem economicamente da tutela do Estado (ARAÚJO et al., 2013). A irrigação pública, segundo BRASIL (2008), sempre teve forte suporte da esfera federal de governo com muitos projetos não tendo alcançado as metas estabelecidas e não apresentando condições de sustentabilidade.

Para Araújo et al., (2013) o incentivo e a adoção desta tecnologia devem estar associados ao debate da sustentabilidade, em função de sua relação com importantes variáveis ambientais como a utilização de recursos naturais, especialmente água, além de sua potencial contribuição para a desertificação.
Os agricultores irrigantes do Perímetro Irrigado Baixo Acaraú, em sua maioria, adotam método de irrigação localizada. Para Bernardo et al., (2006), a irrigação localizada consiste na aplicação de água apenas na parte da área ocupada pelo sistema radicular das plantas, com baixa intensidade e alta frequência, tais como os sistemas microaspersão e gotejamento.

Existem técnicas efetivas para se realizar o manejo de um sistema de irrigação, que vai da simples adoção de calendários de irrigação adequados à implantação de serviços de assessoramento ao irrigante (SAI), que associa uma equipe qualificada com o uso de "softwares" computacionais.

Em 2011, o Instituto de Pesquisa e Inovação na Agricultura Irrigada (Inovagri) iniciou um projeto no Distrito de Irrigação do Baixo Acaraú (Dibau), com o objetivo de desenvolver um modelo de Serviço de Assessoramento ao Irrigante (SAI) adequado às condições do Estado do Ceará (LIMA et al., 2012). A plataforma do sistema S@I desenvolvida no Dibau possui indicadores de desempenho da irrigação que permitem quantificar como a irrigação vem sendo operacionalizada no perímetro.

Um dos indicadores do S@I é o Fornecimento Relativo de Irrigação (FRI), que permite relacionar a quantidade de água utilizada no lote com a demandada através da recomendação de irrigação fornecida pelo serviço de assessoramento ao irrigante (SAI).

Na gestão do Dibau, o FRI auxilia no sentido de identificar os agricultores que utilizam água em excesso, ou seja, sem levar em conta princípios técnicos. Com isso, é possível fazer campanhas de conscientização quanto ao uso racional da irrigação. Também possibilita 
estabelecer estratégias de cobrança pelo uso da água, nas quais privilegie os irrigantes que irrigam adequadamente.

Face ao exposto, a presente pesquisa tem como objetivo utilizar o Fornecimento Relativo de Irrigação (FRI) como estratégia de gestão para sustentabilidade hídrica e econômica do Distrito de Irrigação Baixo Acaraú. Especificamente, a pesquisa visa analisar o desempenho do Distrito de Irrigação por meio dos indicadores Eficiência Financeira, Produtividade da Água, Custo de Um Hectare em Produção e taxa de inadimplência da tarifa de água $K_{2}$.

\section{MATERIAL E MÉTODOS}

Os dados da pesquisa foram obtidos no Perímetro Irrigado Baixo Acaraú, localizado na região Norte do Ceará, no período de setembro a outubro de 2014. De acordo com a classificação de Köeppen, o clima da área é AW', quente e úmido com chuvas de verãooutono, registrando temperaturas médias mensais superiores a $18^{\circ} \mathrm{C}$, com amplitude térmica sempre inferior a $5^{\circ} \mathrm{C}$, e os meses mais quentes são novembro e dezembro.

O período considerado para o levantamento de informações foram os anos de 2012 a 2014, por se tratar de um período onde as chuvas ficaram abaixo da média histórica da região, e por isso foi o período de maior demanda de atividade para o Projeto SAI no Baixo Acaraú.

O indicador Fornecimento Relativo de Irrigação (FRI) do sistema S@I relaciona a quantidade de água utilizada no lote, obtida por meio de leitura mensal no hidrômetro instalado na entrada de cada lote, com a demandada através da irrigação requerida calculada pelo software e fornecido diariamente pelo sistema S@I como recomendação do tempo de irrigação, considerando a vazão aplicada em cada setor do lote medida no campo. O indicador FRI do S@I é obtido conforme equação 01 . No sentido de se obter uma maior precisão no volume de água aplicado e demandado pelas culturas optou-se por trabalhar com lotes cultivados com apenas uma cultura, sendo selecionadas as três principais culturas do Perímetro Irrigado: coco (cocos nucifera), banana (Musa spp) e goiaba (Psidium guajava).

$$
F R I=\frac{\text { Água fornecida ao lote }\left(\mathrm{m}^{3}\right)}{\text { Requerimento de irrigação }\left(\mathrm{m}^{3}\right)}
$$

O Indicador de Eficiência Financeira (EF) do Distrito de Irrigação foi definido pela relação entre o volume de recursos financeiros arrecadados anualmente da tarifa de água (parcela $\mathrm{K}_{2}$ ) e o custo anual de Operação e Manutenção (O\&M) necessário à manutenção e operacionalidade do perímetro irrigado e, conforme a expressão:

$$
E F=\frac{K 2 \text { arrecadado }}{\text { Custo } O \& M}
$$

Em que:

EF: indicador de eficiência financeira $\left(\mathrm{R} \$ \mathrm{R} \$^{-1}\right)$. Custo O\&M: custo anual de operação e manutenção do perímetro $(\mathrm{R} \$)$.

$\mathrm{K}_{2}$ arrecadado: recursos arrecadados no perímetro no ano (R\$).

O custo de Um Hectare em Produção foi definido como sendo o valor necessário para o Distrito operar e manter um hectare cultivado em produção, ou seja, a despesa anual, da infraestrutura de uso comum, realizada para levar a água necessária para irrigação normal do hectare cultivado, nas condições do Perímetro Irrigado, sendo expresso pela relação entre o custo de O\&M pela área cultivada:

$$
I C H P=\frac{\text { Custo } O \& M}{\text { área cultivada }}
$$

Em que:

ICHP: indicador do custo de um hectare em produção ( $\mathrm{R} \$$ ha $\left.^{-1}\right)$

Custo O\&M: custo anual de O\&M do Perímetro Irrigado (R\$)

Área cultivada: área anual cultivada no perímetro (ha).

A Produtividade da Água (IPA) foi definida como a relação entre o valor bruto da produção (VBP) de toda atividade de irrigação do perímetro, pelo volume de água total 
utilizado na irrigação das culturas que geraram a receita. Expresso pela equação a seguir:

$$
I P A=\frac{V B P}{\text { volumed'água }}
$$

Em que:

IPA: índice de produtividade da água $\left(\mathrm{R} \$ \mathrm{~m}^{-3}\right)$ VBP: valor bruto de toda produção do perímetro no ano (R\$).

A Inadimplência da Tarifa D’Água $K_{2}$ a qual demonstra a capacidade de autossustentabilidade do Perímetro Irrigado e a situação econômica de seus irrigantes, e aponta que valores crescentes de inadimplência indicam necessidade de maior atenção ao
Distrito de Irrigação e aos irrigantes foi calculada pela equação 05 .

$$
\text { Inad } K 2=1,0-\left[\frac{K 2 \text { arrecadado }}{K 2 \text { devido }}\right]
$$

Em que:

Inad $K_{2}$ : Inadimplência da tarifa $K_{2}$ no ano (\%).

\section{RESULTADOS E DISCUSSÃO}

O valor ideal para o FRI é igual a 1,0, valores abaixo indicam fornecimento de água inferior à requerida pela cultura. Na Tabela 1 observam-se os valores do indicador Fornecimento Relativo de Irrigação (FRI) para os meses analisados no período.

Tabela 1 - Valores de Fornecimento Relativo de Irrigação (FRI) no Perímetro Irrigado Baixo Acaraú nos anos 2012, 2013 e 2014.

\begin{tabular}{l|cccc|ccccc|ccc}
\hline Ano & \multicolumn{4}{|c|}{2012} & \multicolumn{4}{c|}{$\mathbf{2 0 1 3}$} & \multicolumn{4}{c}{$\mathbf{2 0 1 4}$} \\
\hline Lote - Cultura & Ago & Set & Out & Nov & Ago & Set & Out & Nov & Ago & Set & Out & Nov \\
\hline C 38/2 - Banana & 1,24 & 0,87 & 1,20 & 0,65 & 0,74 & 0,80 & 0,92 & 0,92 & 0,16 & 0,19 & 0,13 & 0,14 \\
C 39/4 - Coco & 0,76 & 1,02 & 0,99 & 1,39 & 0,68 & 0,67 & 0,54 & 0,58 & 0,25 & 0,18 & 0,22 & 0,36 \\
C 181/2 - Goiaba & 0,43 & 3,00 & 3,12 & 2,92 & 0,38 & 1,65 & 1,62 & 1,85 & 0,25 & 0,17 & 0,22 & 0,14 \\
\hline Fonte: (BELTRÃO, 2017) & \multicolumn{1}{|c}{ (B) }
\end{tabular}

De maneira geral observou-se uma queda acentuada nos valores do FRI no período. Esta variação do FRI indica uma redução no fornecimento de água para os lotes nos anos de 2012 a 2014, reflexo da crise hídrica enfrentada pelo perímetro com precipitações abaixo da média anual da região, desde 2011, demonstrando assim a importância do FRI como ferramenta estratégica para a gestão de água no Perímetro Irrigado.

Na Tabela 2 são apresentados os indicadores de Eficiência Econômica. A mesma constitui uma ferramenta fundamental para os gerentes dos Distritos de Irrigação, para os irrigantes e sociedade em geral, tendo em vista os recursos investidos pela União.

Tabela 2 - Indicador de Eficiência Financeira para o Distrito de Irrigação Baixo Acaraú nos anos 2012, 2013 e 2014.

\begin{tabular}{lrrr}
\multicolumn{1}{c}{ Ano } & 2012 & \multicolumn{1}{c}{2013} & \multicolumn{1}{c}{2014} \\
\hline Tarifa K2 arrecadada (R\$) & $1.450 .557,40$ & $1.639 .863,00$ & $3.161 .106,00$ \\
Custo de O \& M (R\$) & $2.932 .898,22$ & $2.932 .898,22$ & $4.478 .809,13$ \\
Eficiência Financeira $\left(\mathrm{R} \$ \mathrm{R} \mathrm{S}^{-1}\right)$ & 0,49 & 0,56 & 0,71 \\
\hline
\end{tabular}

Fonte: Dnocs (2016).

Observa-se que os valores do indicador ficaram abaixo do desejado, tendo em vista que se almejam valores acima ou próximos de 1,0. Demonstrando que apesar do incremento em 2014, a gestão do Distrito ainda não conseguiu atingir o equilíbrio entre as despesas e as receitas, apontando para a necessidade de melhorias para atingir a sustentabilidade financeira na busca da autogestão. Porém, o crescimento do indicador em 2014, pode estar relacionado a uma melhoria na eficiência da gestão do Distrito, uma vez que, apesar da elevada taxa de inadimplência, não foi verificado um crescimento significativo da inadimplência no ano em questão, mesmo no contexto adverso de racionamento de água. 
Deste modo, para que um Perímetro de Irrigação alcance sua autossuficiência financeira, dentre outros fatores é de fundamental importância que o mesmo possua um Distrito de Irrigação administrativamente organizado, que cumpra o seu objetivo de gerenciar, além de atender suas metas e fazer cumprir seus regimentos internos, nos quais devem contemplar regras que permitam o controle efetivo do uso da água pelos usuários.

O Custo de Um Hectare em Produção expressa o custo da infraestrutura de uso comum para manter Um Hectare em produção. Na Tabela 3 verifica-se um crescimento expressivo no valor do indicador em 2014, atribuído ao crescimento no custo de O\&M e redução na área cultivada daquele ano.

Tabela 3 - Custo de Um Hectare em Produção para o Distrito de Irrigação Baixo Acaraú nos anos 2012, 2013 e 2014.

\begin{tabular}{lrrr}
\hline \multicolumn{1}{c}{ Ano } & \multicolumn{1}{c}{2012} & \multicolumn{1}{c}{2013} & \multicolumn{1}{c}{2014} \\
\hline Custo de O\&M (R\$) & $2.932 .898,22$ & $2.932 .898,22$ & $4.478 .809,13$ \\
Área cultivada (ha) & $4.966,21$ & $5.170,73$ & $3.825,75$ \\
Custo de 1,0 ha em Produção $\left(\mathrm{R} \$\right.$ ha $\left.^{-1}\right)$ & 590,57 & 567,21 & $1.170,70$ \\
\hline Fonte: Dnocs (2016). & & &
\end{tabular}

Verifica-se que nos anos de 2012 e 2013 o valor do indicador praticamente se manteve constante. A pequena melhoria no desempenho observada neste período se deve ao aumento da área cultivada no ano de 2013, em relação ao ano anterior, já que o custo de O\&M, naqueles anos, permaneceu constante.

No ano de 2014 se verificou um aumento acentuado no valor do indicador expressando uma queda no desempenho, ou seja, o custo médio, por parte do Distrito de Irrigação Baixo Acaraú, necessário para manter Um Hectare em produção foi de R \$ 1.170,70 (um mil cento e setenta reais e setenta centavos). Considerando que em 2014 o custo de operação e manutenção foi o mais elevado do período em estudo, com $\mathrm{R} \$ 4.478 .809,13$, e o valor anual arrecadado com a tarifa mensal $\mathrm{K}_{2}$ ficou em $\mathrm{R} \$ 3.161 .106,19$, naquele ano, percebe-se um déficit de aproximadamente 29,0\% em relação ao montante necessário para manter Um Hectare em produção.

No entanto, a queda acentuada na área irrigada também contribuiu negativamente para a elevação deste indicador. Este fato já era previsto, pois uma das providências tomada pela gestão para o racionamento d'água foi de inibir a implantação de novos cultivos. Sendo assim, o uso do FRI permitiu o acompanhamento no cumprimento desta determinação, pois a ampliação de áreas cultivadas proporciona um aumento na necessidade de água.

$\mathrm{O}$ indicador Produtividade da Água, obtido para o Perímetro Irrigado Baixo Acaraú no período de 2012 a 2014, bem como os dados utilizados no seu cálculo, estão apresentados na Tabela 4 a seguir.

Tabela 4 - Produtividade da Água para o Distrito de Irrigação Baixo Acaraú nos anos 2012, 2013 e 2014.

\begin{tabular}{lrrr}
\hline \multicolumn{1}{c}{ Ano } & 2012 & \multicolumn{1}{c}{2013} & \multicolumn{1}{c}{2014} \\
\hline VBP (R\$) & $28.499 .350,00$ & $48.605 .296,50$ & $47.172 .800,00$ \\
Volume de água $\left(\mathrm{m}^{3}\right)$ & $51.783 .969,60$ & $46.278 .136,80$ & $28.768 .994,00$ \\
Produtividade da Água - IPA $\left(\mathrm{R} \$ \mathrm{~m}^{-3}\right)$ & 0,55 & 1,05 & 1,64 \\
\hline Fonte: Dnocs (2016). & & &
\end{tabular}

Este indicador está associado à utilização racional da água como fator de produção, consequentemente, a geração de receita bruta por unidade de volume de água utilizado. Observa-se um crescimento no valor deste indicador, tendo atingido 1,64 no ano de 2014, seu maior valor no período em estudo. Significa que para cada $1,0 \mathrm{~m}^{3}$ de água utilizada no Perímetro foi gerada uma receita bruta de R\$ 1,64 em 2014. 
O maior valor observado em 2014 está associado ao crescimento do VBP. No entanto, em 2014 o Perímetro vivenciava sérias restrições hídricas, culminando na implantação de ações para o racionamento d'água. O crescimento no valor do indicador expressa o uso mais racional da água, elevando a eficiência do sistema para obter mais renda por $\mathrm{m}^{3}$ utilizado. A gestão do Distrito de Irrigação pode acompanhar o consumo da água de forma individualizada, ou seja, de cada irrigante através do FRI.

A tarifa mensal d'água $\mathrm{K}_{2}$ correspondente ao valor das despesas de administração, operação, conservação e manutenção da infraestrutura de uso comum. A Tabela 5 apresenta os valores anuais de $\mathrm{K}_{2}$ devido e arrecadado do Perímetro Irrigado Baixo Acaraú no período de 2012 a 2014.

Tabela 5 - Cálculo da Inadimplência da Tarifa D’Água K2 para o Perímetro Irrigado Baixo Acaraú nos anos 2012, 2013 e 2014.

\begin{tabular}{lrrr}
\hline \multicolumn{1}{c}{ Ano } & \multicolumn{1}{c}{2012} & \multicolumn{1}{c}{2013} & \multicolumn{1}{c}{2014} \\
\hline Tarifa $\mathrm{K}_{2}$ devida (R\$) & $2.086 .058,25$ & $2.284 .506,24$ & $4.556 .317,50$ \\
Tarifa $\mathrm{K}_{2}$ arrecadada (R\$) & $1.450 .557,40$ & $1.639 .863,00$ & $3.161 .106,19$ \\
Inadimplência da Tarifa $\mathrm{K}_{2}(\%)$ & 0,30 & 0,28 & 0,31 \\
\hline
\end{tabular}

Fonte: Dnocs (2016).

Os valores definidos em assembléia pela Associação de Produtores do Distrito de Irrigação do Baixo Acaraú para tarifa de $\mathrm{K}_{2.1}$ eram de $\mathrm{R} \$ 19,00 /$ ha para pequeno produtores e técnicos, e, R\$22,00/ha para empresários nos anos de 2012 e 2013, com aumento de $\mathrm{R} \$ 2,00 /$ ha para as duas categorias em 2014. Já a tarifa de $\mathrm{K}_{2.2}$ passou de $\mathrm{R} \$ 8,00 / \mathrm{m}^{3}$ em 2012 e 2013, para $\mathrm{R} \$ 9,00 / \mathrm{m}^{3}$ em 2014. Estes aumentos foram necessários devido à séria situação de restrição hídrica pela qual passava o Perímetro neste período, objetivando um equilíbrio da receita tendo em vista a redução no volume de água disponível aos irrigantes e também fazer frente a um aumento de 34,5\% no Custo de Operação e Manutenção do Perímetro em 2014 comparado ao ano anterior.

Considera-se que o Perímetro atinge seu equilíbrio financeiro quando não necessita mais de recursos do Governo para o seu funcionamento, conseguindo manter seus compromissos em dia, inclusive o pagamento da parcela da tarifa $K_{1}$, que é tarifa de amortização do investimento feito pelo Governo no projeto.

Verifica-se pouca variação na taxa de inadimplência da tarifa, a qual é considerada muito elevada. Os fatores que contribuíram para o aumento da arrecadação em 2014 foram o aumento de $\mathrm{R} \$ 2,00$ e $\mathrm{R} \$ 1,00$ nos valores das tarifas de $\mathrm{K}_{2}$ fixa e variável respectivamente. $\mathrm{O}$ indicador expressa que apesar das dificuldades enfrentadas pelo Perímetro durante o período de escassez hídrica a administração tem conseguido manter o nível de arrecadação, o que também pode ser atribuído ao crescimento no Valor Bruto da Produção (VBP) devido ao aumento nos preços dos produtos.

O crescimento no valor do indicador expressa o uso mais racional da água, elevando a eficiência do sistema para obter mais renda por $\mathrm{m}^{3}$ utilizado. A gestão do Distrito de Irrigação pode acompanhar o consumo da água de forma individualizada, ou seja, de cada irrigante através do FRI.

\section{CONCLUSÕES}

O Fornecimento Relativo de Irrigação apresentou uma queda anual refletindo os efeitos acumulativos da escassez hídrica no Perímetro Irrigado Baixo Acaraú, não obstante do ponto de vista financeiro perceber-se uma evolução na gestão do Distrito de Irrigação Baixo Acaraú.

A elevação na produtividade da água e a manutenção no VBP e na arrecadação da tarifa $\mathrm{K}_{2}$ foram fatores que contribuíram de forma positiva. Porém, apesar da evolução no indicador Eficiência Financeira, o Distrito ainda carece de ajustes administrativos para atingir a autogestão, tendo em vista o elevado custo de O\&M, o aumento no custo para o Dibau manter Um Hectare em produção, além da taxa de 
inadimplência da tarifa $K_{2}$, considerada muito elevada.

Estes resultados demonstram a importância do FRI para a gestão do Distrito de Irrigação do Baixo Acaraú, na busca da sustentabilidade hídrica, permitindo identificar os agricultores que utilizam água em excesso ou déficit, sem levar em conta princípios técnicos. Permite ainda realizar campanhas de conscientização quanto ao uso da água, e estabelecer estratégias de cobrança da mesma, além de bonificar pelo manejo racional da irrigação.

Assim, especificamente em 2014, o FRI foi importante como instrumento auxiliar na tomada de decisão, permitindo um equilíbrio na gestão em meio à crise hídrica.

\section{REFERÊNCIAS BIBLIOGRÁFICAS}

ARAÚJO, S. M. S. A Região Semiárida do Nordeste do Brasil: Questões Ambientais e Possibilidades de uso Sustentável dos Recursos. Revista Rios Eletrônica - Fasete, v. 5, n.5, 2011.

BERNARDO, S.; SOARES, A. A.; MANTOVANI, E. C. Manual de irrigação. 8 ed. Viçosa: Ed. UFV, 2006. 625p.

BRASIL. Ministério da Integração Nacional/Instituto Interamericano de Cooperação para a Agricultura. A irrigação no Brasil: situação e Diretrizes. Brasília, DF, 2008.
DIÓGENES, F. C. A. Indicadores de desempenho para o perímetro irrigado de brumado na perspectiva de sua autogestão. Fortaleza, 2008. 76f. Dissertação (Mestrado em engenharia agrícola) - Universidade Federal do Ceará, UFC.

DNOCS, Perímetro Irrigado Baixo Acarau. Disponível em: http://www.dnocs.gov.br/ dnocs/doc/canais/per imetros_irrigados/ce/baixo_acarau.html.

FRANÇA, F. M. C. (coord.) A importância do agronegócio da irrigação para o desenvolvimento do Nordeste. Políticas e estratégias para um Novo Modelo de Irrigação. Fortaleza: Banco do Nordeste, 2001, v. 1, 114 p. Acesso em: 13 jan. de 2016.

GALVÍNCIO, J. D.; MOURA, M. S. B. de. Aspectos climáticos da captação de água de chuva no Estado de Pernambuco. Revista de geografia, v.22, n.2, p.96-113, 2005.

LIMA, S. C. R. V.; FRIZZONE, J. A.; SOUSA, A. E. C.; JÚNIOR, J. A. B.; FERREIRA, R. P.; GARCIA, D. R. Aplicação da tecnologia da informação e a adoção pelo agricultor: a avaliação inicial do envio de mensagens pelo serviço de assessoramento ao irrigante. Revista Brasileira de Agricultura Irrigada. v. 6, n. 4, p. 314-328, 2012.

PEREIRA, A. W. R. Transferência de Gestão da Irrigação: Um Estudo no Perímetro Irrigado de São Gonçalo/PB. REUNIR: Revista de Administração, Contabilidade e sustentabilidade. v. 5, n. 2, p .85-103, 2015. 